\title{
CFD Analysis of DI Diesel Engine using Exhaust Gas Recirculation
}

\author{
Sk. Mohammad Shareef ${ }^{1}$, A.L.N. Arun Kumar ${ }^{2}$ and T. Venkatesh ${ }^{3}$ \\ ${ }^{1}$ Asst. Professor, CVR College of Engineering/Mechanical Engg. Department, Hyderabad, India \\ Email: shareefshaik4@gmail.com \\ ${ }^{2}$ Asst. Professor, CVR College of Engineering/Mechanical Engg. Department, Hyderabad, India \\ Email: aln.arunkumar@gmail.com \\ ${ }^{3}$ Asst. Professor, CVR College of Engineering/Mechanical Engg. Department, Hyderabad, India \\ Email: venkatesh2711991@gmail.com
}

\begin{abstract}
NOx is produced by a diesel engine due to high temperatures available in the combustion chamber. Nitrogen is in diatomic nature in the air, but at high temperatures available in the combustion chamber, it will divide into monatomic form and this monatomic nitrogen reacts with Oxygen to form NOx. To reduce this NOx formation in the diesel engine oxygen content is to be reduced in the intake air. It will be achieved by re-circulating some amount of exhaust gas into the combustion chamber through intake air.

This present work discusses the piston bowl design and control of nitric oxides by using exhaust gas recirculation in direct injection diesel engine. Hemispherical piston bowl of the direct injection diesel engine is created with the help of PRO-E software. This piston is used in CFD for analysis of emissions reduction by the method of Exhaust gas recirculation at different percentages. It is proposed to analyze this in CFD by using STAR-CD as a tool.
\end{abstract}

The results, which are obtained from the CFD are compared with Experimental results which are available in the literature.

Index Terms: Hemispherical piston bowl, PRO-E, Direct injection diesel engine, piston bowl, Exhaust gas recirculation, CFD, NOx emissions, CO Emissions.

\section{INTRODUCTION}

Enhancing combustion engine efficiency is a prime concern today. Plenty of research has gone in to improving the thermal efficiency of the Internal Combustion Engines, to urge more work from the identical amount of fuel burned and also the energy present within the combustion chamber just part, which gets changed over into useful output power. Because combustion happens inside the combustion chamber, the performance of the internal combustion engine relies greatly on the cylinder bowl shape. The complete combustion depends on the amount of air entered the combustion chamber and movement of air. This movement of the air is controlled by cylinder bowl shapes. Thus, there are different varieties of bowl shapes like shallow, hemispherical, cylindrical and toroidal.

The present study focuses on the combustion chamber area of a single-cylinder diesel engine with a specification of 5HP, $1500 \mathrm{rpm}$. The use of piston crowns in a top portion of piston is the most advantageous for proper combustion timing and increasing the volumetric efficiency of the engine. CFD analysis of the diesel engine has been carried out with hemispherical bowl geometry validated with experimental data. From the available results, it is concluded that there is a reasonable agreement between CFD and experimental results.

Jaffer Hussain et.al. [1] has conducted an experiment on the direct injection diesel engine to reduce $\mathrm{NO}_{\mathrm{x}}$ emissions by using method exhaust gas recirculation at $0 \%$ EGR, $5 \%$ EGR, $10 \%$ EGR and $15 \%$ EGR. The performance characteristics like Thermal efficiency, Basic fuel consumption, and volumetric efficiency calculated, and emission charecteristics like $\mathrm{NO}_{\mathrm{x}}$ and $\mathrm{CO}$ values are observed in results.

NV Raghavendra reddy and Dr. Jayashankara [2] have conducted CFD simulation on a direct injection diesel engine with a flat head and $\mathrm{W}$ shape toroidal piston. The cylinder temperature, cylinder pressure, Apparent heat release, NOx, CO emissions, and soot are calculated and discussed in results.

A.M. Indoria et.al.[3] has investigated the geometry of different combustion chamber of direct injection diesel engine by CFD modelling of in-cylinder flow and concluded which geometry gives more swirl motion of air and calculates the NOx emissions and compared these results with experimental data.

B. Jayashankara and V.Ganesan[4] have studied the effect of fuel injection timing and intake pressure on the performance of direct injection diesel engine and performance characteristics of the engine are investigated at different transient conditions using CFD. The results which are obtained by CFD are validated with experimental results. Emissions like NOx and soot are presented and discussed in results.

Dr.G.Prasanthi and E Anitha [5] have conducted an experiment on the direct injection diesel engine to investigate the effect of exhaust gas recirculation and calculated the performance and emission characteristics by using Moringa Oliefera oil as biodiesel. This paper concluded that how the emissions and performance characteristics are changed by changing the bio-diesel percentage and EGR rate.

Kota Sridhar et.al.[6] has conducted a computerized simulation of the spark-ignition internal combustion engines. The discrete phase model is used for simulating fuel injection, evaporation, and droplet boiling. The simulation model developed for the single-cylinder sparkignition engine operating with hexane as fuel and results were noted with different crank angles at a different flow rate. 
S Gavudhama Karunanidhi et.al [7] has conducted simulation on direct injection diesel engine by split injection. The performance characteristics and emissions characteristics like Engine efficiency, NOx, and soot are presented and discussed in results.

Shengli Wei et.al.[8] has conducted numerical analysis on direct injection diesel engine by changing the swirl ratios on the swirl chamber and results are observed.

V Kolhe et.al.[9] has conducted simulation on direct injection diesel engine with Pongamia pinnta oil as biodiesel in Computational Fluid Dynamics using FLUENT as a tool and compared these results with experimental results.

V. Kongre and Vivek K.Sunnapwar [10] have conducted simulation work on a direct injection diesel engine fueled with diesel in CFD using FLUENT as a tool and compared Cylinder pressure, Cylinder temperature with experiment data in results.

In this project, the exhaust gas recirculation method is used for reducing emissions of direct injection diesel engine by changing the different rates of EGR using CFD analysis by concluding which rate is best for diesel engine

\section{Computational Procedure}

The computational mesh is created using either the "Trimming" or the "Mapping" method.

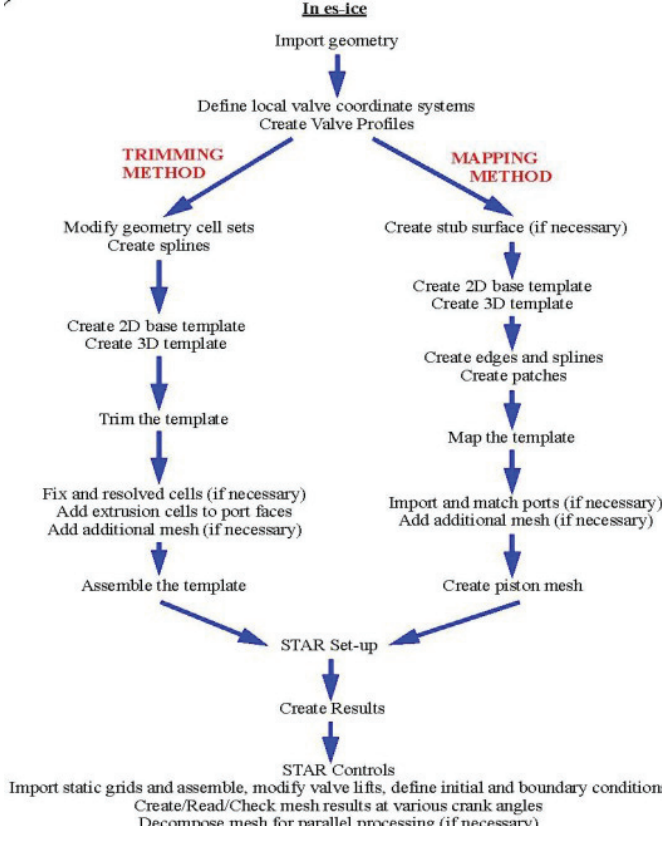

Figure1. Basic steps creating computational mesh

Fig. 1 shows the basic steps to create computational piston mesh which is used in CFD for analysis purpose.

Pro-STAR is the general pre-/post-processor of the STAR-CD suite, both the model and CFD analysis parameters need to be defined in pro-STAR, after one has finished working in es-ice. Analyses can be run using serial or parallel processing shown in Fig.2

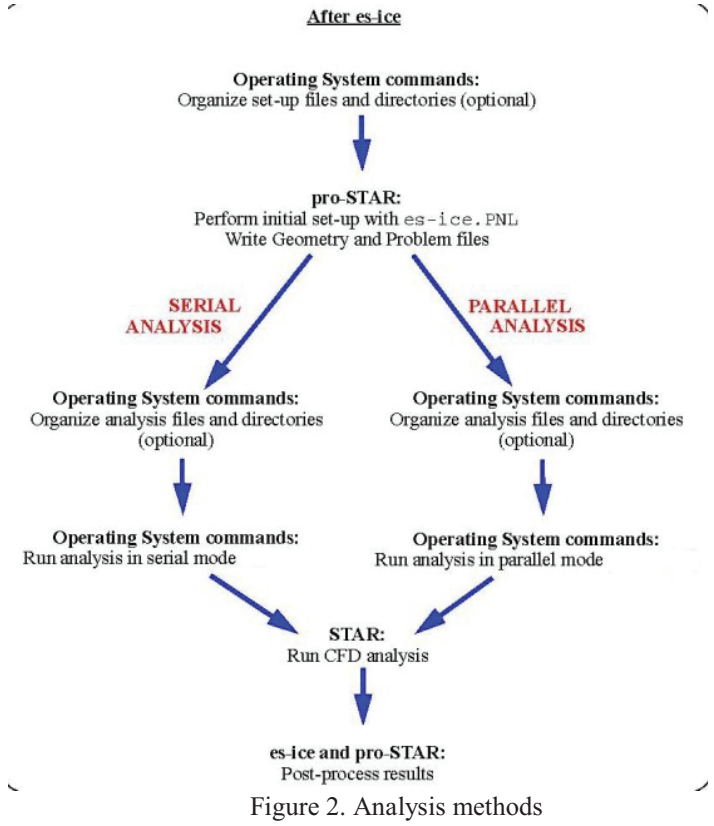

\section{A. Generating piston bowl geometry}

CFD simulation begins with the geometry of the piston bowl. The piston bowl shape is prepared from the standard computer-aided-design-package. The co-ordinates are got from the piston crown. After getting co-ordinates of the piston by using commands which is available in the es-ICE (Expert system - Internal combustion engine) the vertexes are created.

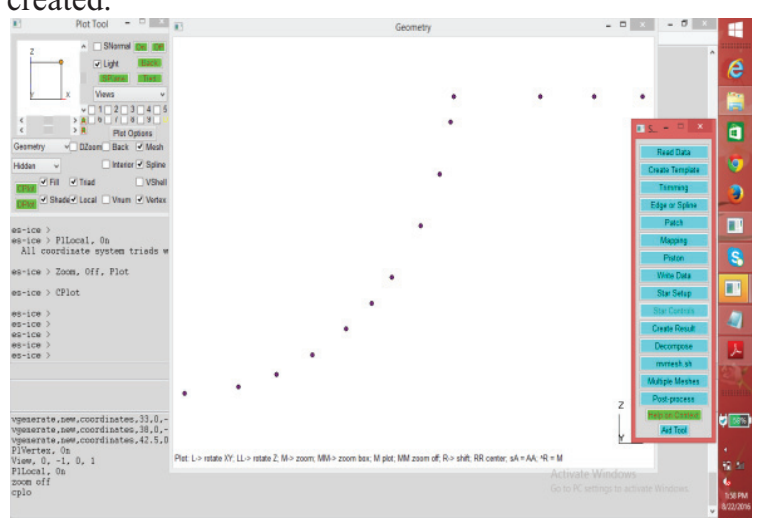

Figure 3. Vertices on geometry window

Fig. 3 shows the vertices created on the geometry window. After creating vertices using the spline command, the spline is created in the geometry window. 


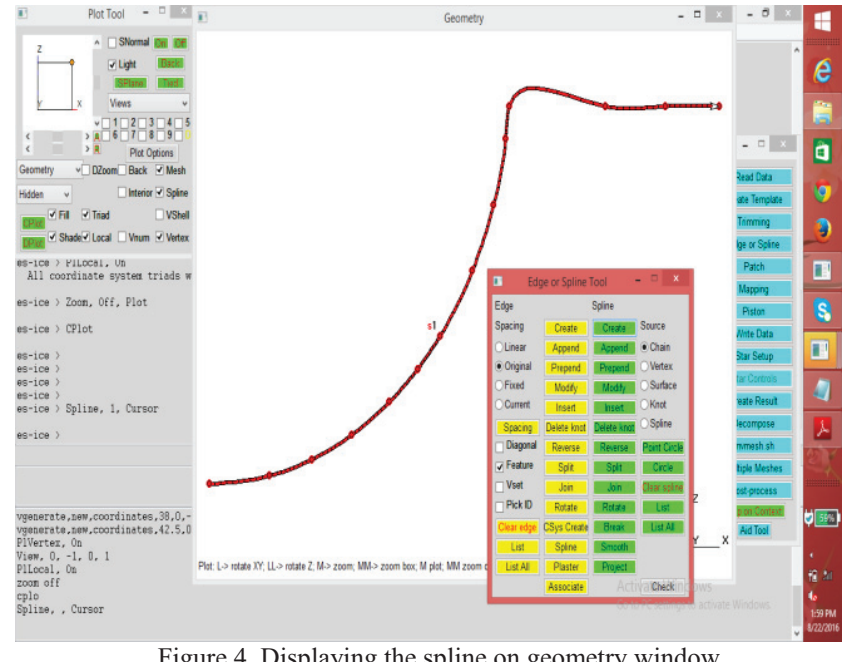

Fig.4 Shows the spline representing the bowl shape after joining the vertices.

The final stage in the sector meshing process is to trim the bowl splines and generate the 3D sector mesh representing the cylinder sector. A 45-degree sector mesh is made taking advantage of the symmetric form of cylinder domain.

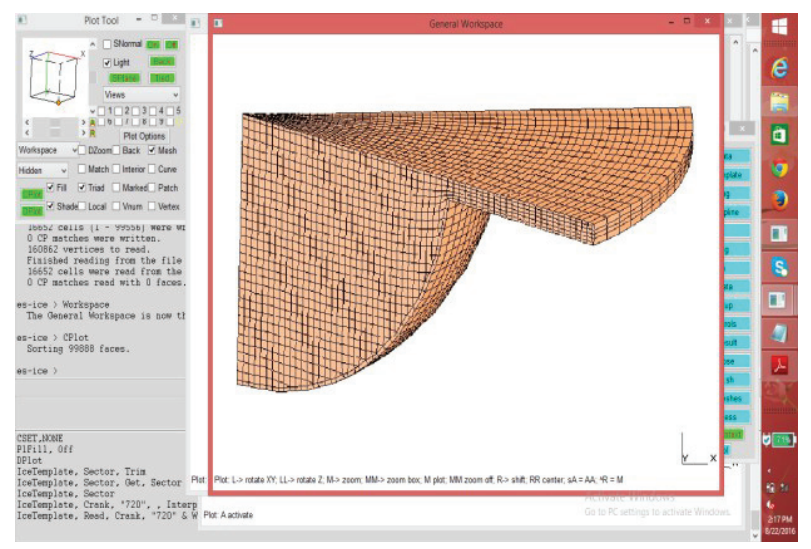

Figure 5. A 45 degree Sector mesh at BDC

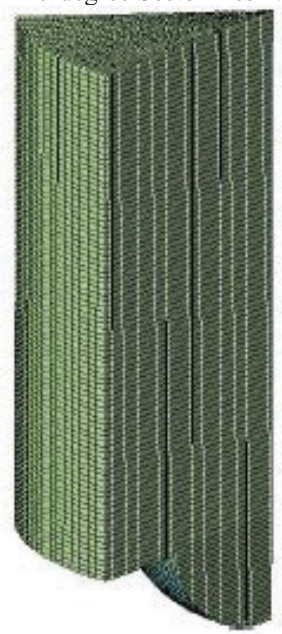

Fig.5 and Fig.6 show the sector mesh at Bottom dead center and Top dead center of the piston.

This 45-degree sector mesh is used for analysis in CFD software.

B. Boundary Conditions.

TABLE I.

INPUT PARAMETERS OF CFD DOMAIN

\begin{tabular}{|l|l|}
\hline Parameter & magnitude \\
\hline Crank shaft speed & $1500 \mathrm{rpm}$ \\
\hline Crank radius & $47 \mathrm{~mm}$ \\
\hline Bore & $85 \mathrm{~mm}$ \\
\hline Stroke & $110 \mathrm{~mm}$ \\
\hline Fuel & HSD \\
\hline
\end{tabular}

Table 1 shows the boundary conditions used for simulation purpose in CFD.

The temperature and pressure available within the combustion chamber of an immediate injection internalcombustion engine are high because of high compression ratios within the combustion chamber of an immediate injection a direct to regulate this high temperature and pressure available within the combustion chamber, a tiny low amount of exhaust gas is mixed with fresh air then introduced into the combustion chamber. This modifies the fuel/air ratio and EGR, which lowers the high temperature in order that the chemical action rate between nitrogen and any unused oxygen is strongly reduced. The engine parameters are applied to $45^{\circ}$ Sector mesh for simulation. The CFD Simulation starts at $680{ }^{\circ} \mathrm{CA}$ to $800{ }^{\circ} \mathrm{CA}$ because this is often the crucial period of investigation towards the evaluation performance and pollutant formation.

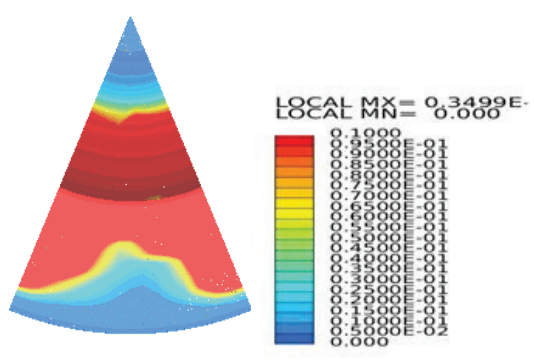

a) Temperaure contour of piston bowl at $0 \%$ EGR

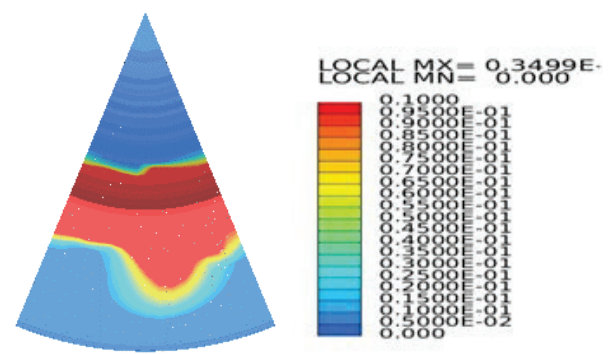

b)Temperaure contour of piston bowl at 5\% EGR

Figure 6. A 45 degree Sector mesh at TDC 


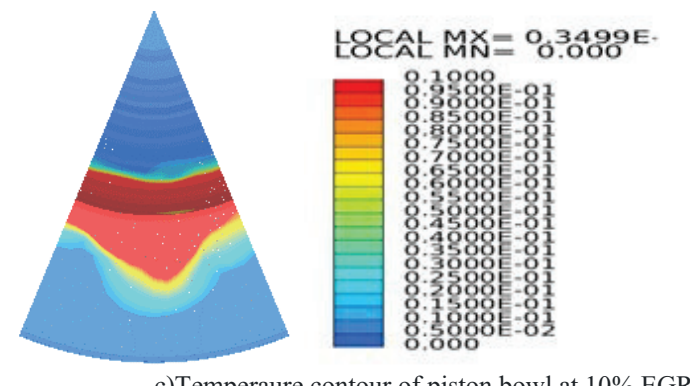

c)Temperaure contour of piston bowl at $10 \%$ EGR

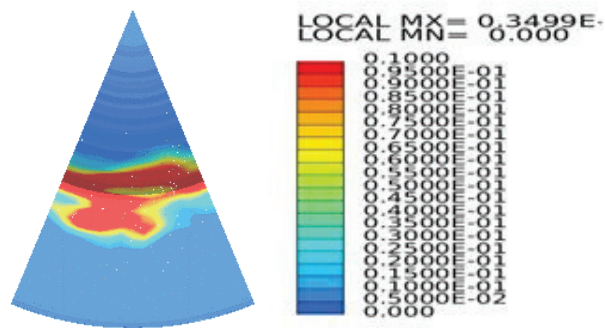

d)Temperaure contour of piston bowl at $15 \%$ EGR Figure 7. Temperature contours at different EGR Levels

From Fig.7 it is observed that the temperature contours, high for the piston when the exhaust gas recirculation is more i.e $0 \%$. Because of the high reactions present between oxygen and nitrogen atoms. The temperature contours are decreasing with increasing the EGR levels from $0 \%$ to $15 \%$. At $15 \%$ EGR the temperature contours are less because of the less reaction present between nitrogen and oxygen.

\section{RESULTS AND DISCUSSIONS}

To verify the results from the simulation, the pressure data computed is compared against experimental data from Dr.G.Prasanthi and E.Anith [5]. Table 2 shows the specifications of engine dimensions and combustion parameters. Validation of the current simulation work is carried out with experimental data of Dr.G.Prasanthi and E.Anitha [5]. The computed in-cylinder pressure data from numerical simulation are in good agreement with the experimental data.

TABLE II.

ENGINE SPECIFICATIONS

\begin{tabular}{|c|l|l|}
\hline S.No & Particulates & Specifications \\
\hline 1 & Engine & $\begin{array}{l}\text { KIRLOSKAR } \\
\text { ENGINE }\end{array}$ \\
\hline 2 & Type & Water cooled \\
\hline 3 & Ignition system & $\begin{array}{l}\text { Compression } \\
\text { ignition }\end{array}$ \\
\hline 4 & $\begin{array}{l}\text { Cylinder } \\
\text { arrangement }\end{array}$ & Vertical \\
\hline 5 & Maximum speed & $1500 \mathrm{rpm}$ \\
\hline 6 & Number of Cylinder & 1 \\
\hline 7 & Bore & $85 \mathrm{~mm}$ \\
\hline 8 & Stroke & $110 \mathrm{~mm}$ \\
\hline 9 & Compression Ratio & $16.5: 1$ \\
\hline 10 & Maximum HP & $5 \mathrm{HP}$ \\
\hline 11 & Fuel & HSD \\
\hline
\end{tabular}

A. Cylinder Pressure

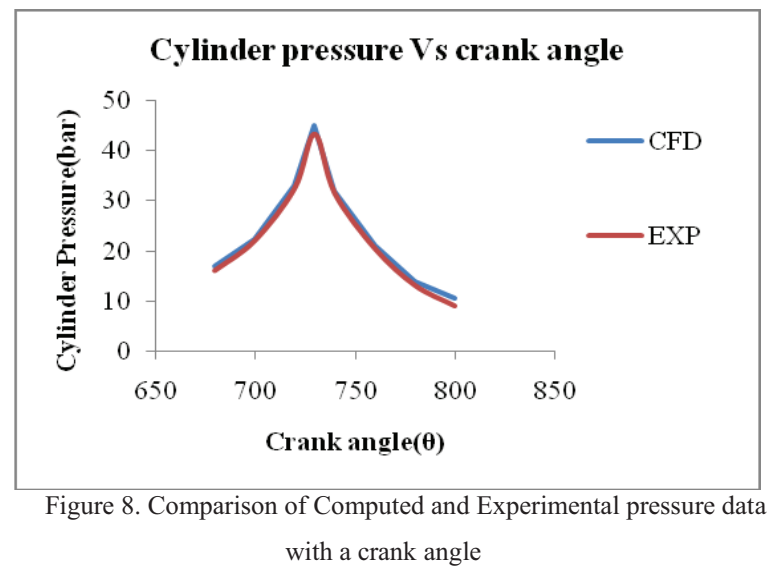

Fig. 8 shows the variation cylinder pressure with respect to the crank angle for CFD and Experimental. It is observed that cylinder pressure from CFD is 45 bars and from experimental is 43.2 bars.

\section{B. Cylinder Temperature}

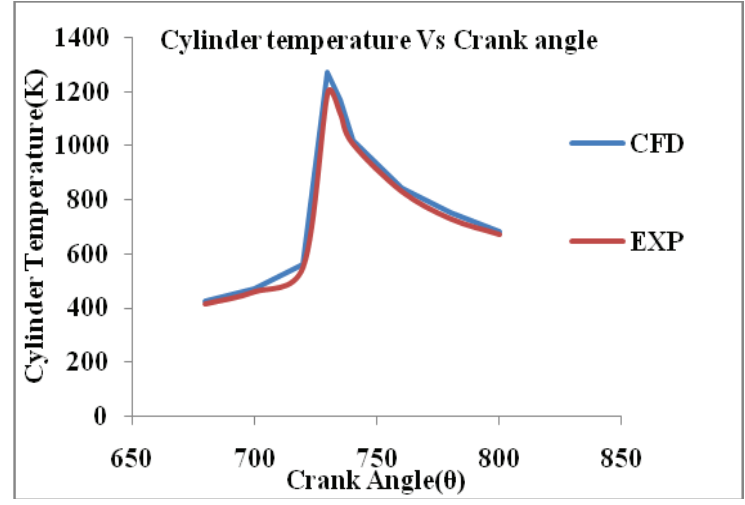

Figure 9. Comparison of Computed cylinder temperature and Experimental cylinder temperatures with a crank angle

Fig.9 shows the variation cylinder temperature with respect to the crank angle for CFD and Experimental. It is observed that cylinder temperature from CFD is $1250^{\circ} \mathrm{K}$ and from experimental is $1197^{\circ} \mathrm{K}$.

\section{Cylinder Pressure at different EGR}

Cylinder parameters such as pressure, temperature, NOx, and soot emissions are predicted numerically for the same piston geometry which is used by Dr.G.Prasanthi and E.Anith[5].EGR is varied from $0 \%$ to $15 \%$. This is normally achieved in a heavy-duty direct injection diesel engine. The cylinder pressures increase till 736 deg Crank angle due to diffusion combustion and thereafter decreases as expected. It is found that the peak pressure during the simulation reaches nearly 45 bars at nearly $740{ }^{\circ} \mathrm{Crank}$ angle for $0 \%$ of EGR, at $15 \%$ EGR, the cylinder pressure drops to 39 bars is shown in Fig10. 


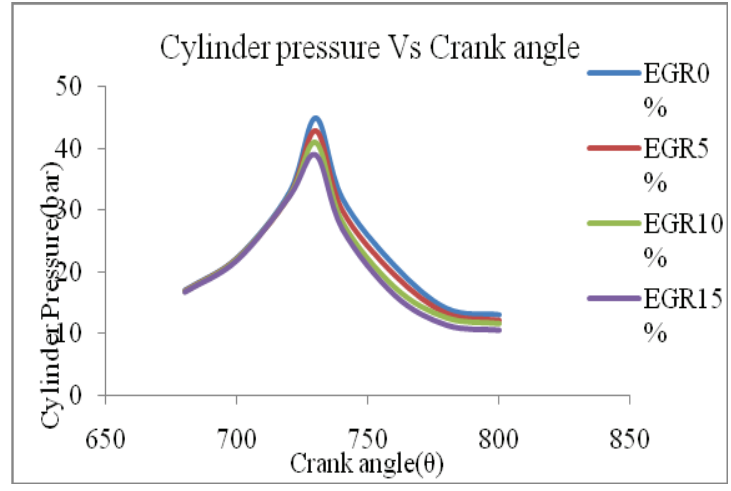

Figure 10. The variation of cylinder pressure with a crank angle at different EGR

\section{Cylinder Temperature at different EGR}

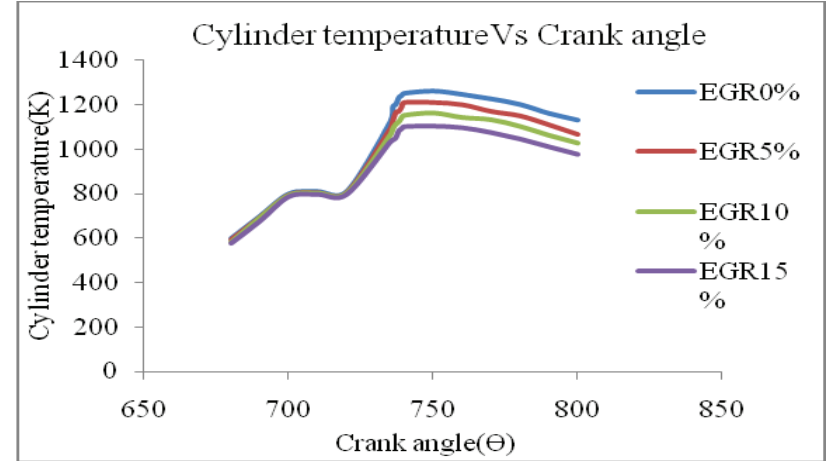

Figure 11. The variation of cylinder temperature with a crank angle at different EGR

Fig. 11 shows the cylinder temperature with a crank angle at different EGR levels. It is observed that peak cylinder drops from $1250^{\circ} \mathrm{K}$ to $1102{ }^{0} \mathrm{~K}$ as EGR has increased from $0 \%$ to $15 \%$. It can be observed that the cylinder temperature is lowered as EGR increased from $0 \%$ to $15 \%$.

E. Apparent Heat Release at different EGR

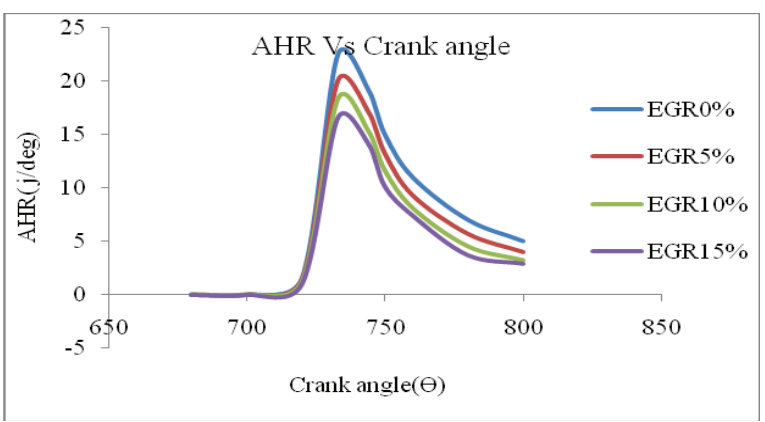

Figure 12. The variation of apparent heat release with a crank angle at different EGR

Fig.12 shows the Apparent hear release with the crank angle at different EGR levels. It is observed that apparent heat release drops from 22.5 joules/deg to 16.5 joules/deg EGR increased from $0 \%$ to $15 \%$. It is observed that the apparent heat release is lowered as EGR increased from $0 \%$ to $15 \%$.

\section{E. $N O_{x}$ at different EGR}

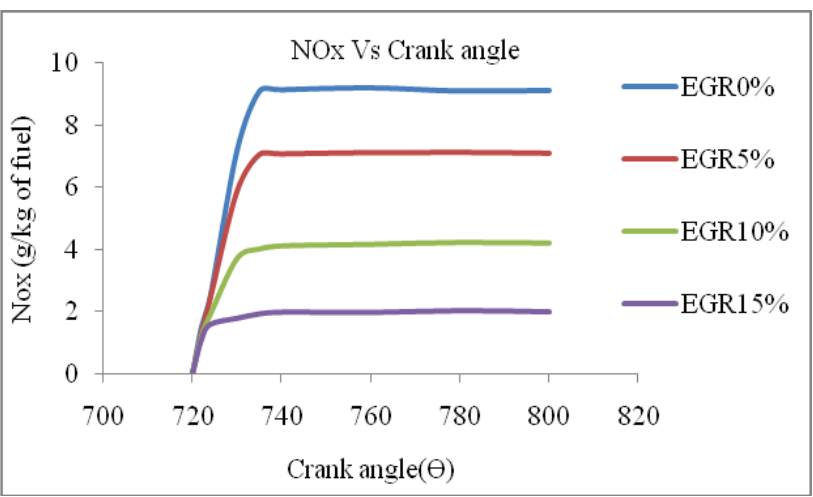

Figure 13. The variation of NOx with a crank angle at different EGR

Fig. 13 shows that NOx formation with a crank angle at different EGR levels. It is observed that the reduction of nitrogen oxide levels from $9.1 \mathrm{~g} / \mathrm{kg}$ of fuel to $2.01 \mathrm{~g} / \mathrm{kg}$ of fuel. NOx increases due to the peak temperature rises.

\section{F. Soot at different EGR}

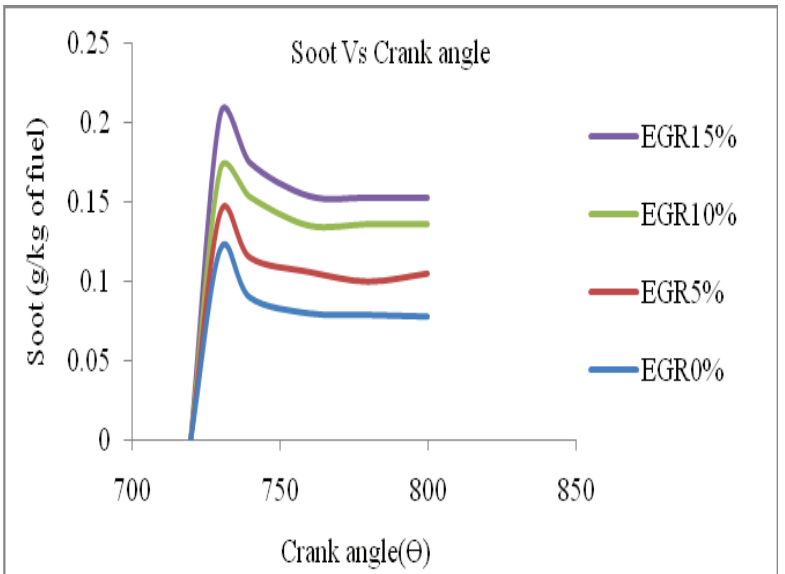

Figure 14. The variation of Soot with a crank angle at different EGR

Fig.14 shows the soot formation at different EGR levels with respect to the crank angle. The soot levels rise from $0.08 \mathrm{~g} / \mathrm{kg}$ of fuel to $0.182 \mathrm{~g} / \mathrm{kg}$ of fuel. This is due to improper combustions the reaction is regressed when EGR is increased. Soot is formed from unburned fuel that nucleates from the vapor phase to a solid phase in fuel-rich regions at elevated temperatures.

TABLE III

COMPARISON BETWEEN CFD AND EXPERIMENTAL WORK

\begin{tabular}{|l|l|l|}
\hline & CFD & Experimental Work \\
\hline Pressure (bars) & 45 & 43.2 \\
\hline Temperature $\left({ }^{\circ} \mathrm{K}\right)$ & 1250 & 1197 \\
\hline
\end{tabular}


Table. 3 shows that the values of pressure and temperature from experimental work are nearer to the values obtained by CFD.

TABLE IV.

COMPARISON OF PRESSURE, TEMPEARTURE, NOX, APPARENT HEAT RELEASE AND SOOT AT DEFFERERNT EGR LEVELS

\begin{tabular}{|c|c|c|c|c|c|}
\hline & $\begin{array}{l}\text { Pressure } \\
\text { (Bar) }\end{array}$ & $\begin{array}{l}\text { Temperature } \\
\left({ }^{0} \mathrm{~K}\right)\end{array}$ & $\begin{array}{l}\text { Apparent } \\
\text { Heat } \\
\text { Release } \\
\text { (joules/deg) } \\
\end{array}$ & $\begin{array}{l}\mathrm{No}_{\mathrm{x}} \\
(\mathrm{g} / \mathrm{kg} \\
\text { of } \\
\text { fuel }) \\
\end{array}$ & $\begin{array}{l}\text { Soot } \\
\text { ( } \mathrm{g} / \mathrm{kg} \text { of } \\
\text { fuel) }\end{array}$ \\
\hline $0 \%$ EGR & 45 & 1250 & 22.5 & 9.1 & 0.08 \\
\hline $5 \%$ EGR & 42 & 1192 & 19.3 & 7.5 & 0.14 \\
\hline $10 \%$ EGR & 40 & 1153 & 17 & 3.9 & 0.165 \\
\hline $15 \%$ EGR & 39 & 1102 & 16.5 & 2.01 & 0.182 \\
\hline
\end{tabular}

Table.4 shows the values of pressure, temperature, apparent heat release, $\mathrm{NO}_{\mathrm{x}}$, and soot of a direct injection diesel engine at $0 \% \mathrm{EGR}, 5 \% \mathrm{EGR}, 10 \% \mathrm{EGR}$ and $15 \%$ EGR.It is observed that pressure is decreased from 45 bars to 39 bars, the temperature is decreased from $1250 \mathrm{~K}$ to $1102 \mathrm{~K}$, apparent heat release is decreased from $22.5 \mathrm{j} / \mathrm{deg}$ to $16.5 \mathrm{j} / \mathrm{deg}, \mathrm{NO}_{\mathrm{x}}$ is decreased from $9.1 \mathrm{~g} / \mathrm{kg}$ of fuel to 2.01 $\mathrm{g} / \mathrm{kg}$ of fuel and soot is increased from $0.08 \mathrm{~g} / \mathrm{kg}$ of fuel to $0.182 \mathrm{~g} / \mathrm{kg}$ of fuel. Soot is increased due to improper combustion.

\section{Conclusions}

This paper concludes that by varying the rates of exhaust gas recirculation there is a reduction in NOx emissions due to the decrease of the cylinder pressure and temperature.

It is observed that at $15 \%$ of the EGR rates the engine produced fewer emissions than that of $0 \%$ EGR.

\section{REFERENCES}

[1] Jaffar Hussain, K. palaniradja, and N. Alagumurthi, R. Manimaran, "Effect of Exhaust Gas Recirculation (EGR) on Performance and Emission characterstics of a Three-cylinder Direct injection Compression Ignition Engine" Alexandria Engineering Journal (2012)51, 241-247.
[2] Raghavendra Reddy NV and Dr. Jayashankara B "CFD Simulation of Direct Injection CI Engine with Flat Piston Bowl and W Shape Toroidal Piston Bowl Combustion Process", Journal of Engineering Research and Application www.ijera.com ISSN: 2248-9622, Vol. 8, Issue5 (Part -IV) May 2018, pp 56-61.

[3] A.M. Indrodia, N.J. Chotai, and B.M.Ramani "Investigation Of Different Combustion Chamber Geometry Of Diesel Engine Using Cfd Modelling of In cylinder Flow for Improving the Performance of Engine.", 5th International \& 26th All India Manufacturing Technology, Design and Research Conference (AIMTDR 2014) December 12th-14th, 2014, IIT Guwahati, Assam, India

[4] B. Jayashankara and V. Ganesan "Effect of fuel injection timing and intake pressure on the performance of a DI diesel engine - A parametric study using CFD”, Energy Conversion and Management 51 (2010) 1835-1848.

[5] Dr,G.Prasanthi and E .Anitha "Experimental investigation on the effect of exhaust gas recirculation on performance and emission characteristics of diesel engine fueled with moringa oleifera oil", International Journal Of Trend in Research and Development (IJTRD), e-ISSN:2394-9333, Volume.2,Issue5, September-October 2015.

[6] Kota Sridhar, R.B.V.Murali, Sk.Mohammad Younus and K.Mohan Lakshmi "Computerised Simulation of Spark Ignition Internal Combustion Engine", IOSR Journal of Mechanical and Civil Engineering (IOSR-JMCE) e-ISSN: 2278-1684 Volume 5, Issue 3 (Jan. - Feb. 2013), PP 05-14.

[7] S Gavudhama karunanidhi, Manu Narayanan P M. G Subba Rao and S G Karunanidhi et al "CFD Studies of Split Injection on the Combustion and Emission Characteristics in DI Diesel Engine" Int. Journal of Engineering Research and Applications. ISSN: 2248-9622, Vol. 4, Issue 7(Version 1), July 2014, pp.55-58.

[8] Shengli Wei, Feihu Wang, Xianyin Leng, Xin Liu and Kunpeng "Numerical analysis on the effect of swirl ratios on swirl chamber Combustion system of DI diesel engines" Energy Conversion and Management 75 (2013) 184-190.

[9] V. Kolhe, Rajesh E. Shelke and S. S. Khandare Jordan "Combustion Modeling with CFD in Direct Injection CI Engine Fuelled with Biodiesel", Journal of Mechanical and Industrial Engineering, Volume 9 Number 1, February.2015 ISSN 1995-6665 Pages 61- 66.

[10] V. Kongre andVivek K. Sunnapwar "CFD Modeling and Experimental Validation of Combustion in Direct Ignition Engine FueledwithDiesel”, International Journal Of Applied engineering Research,Dindigul Volume 1, No 3, 2010, Issn 0976-4259 Pages 509-517. 